\title{
Editorial
}

\section{5th Peer Review Week: Perspectives from European Association of Science Editors and the Asian Council of Science Editors}

\author{
Maryam Sayab \\ Asian Council of Science Editors, Dubai, UAE; maryamsayab@theacse.com; ORCID: 0000-0001-7695-057X \\ Muhammad Sarwar \\ Asian Council of Science Editors, Dubai, UAE; ORCID: 0000-0001-9537-2541 \\ Duncan Nicholas \\ DN Journal Publishing Services, Brighton, UK; ORCID: 0000-0001-8747-4484
}

\section{DOI:10.20316/ESE.2019.45.19018}

The peer review process not only confirms the quality and integrity of research work, but also reinforces the legitimacy of academic journals, and as such, is a valuable process underpinning the scholarly publishing industry. Peer Review Week $(\mathrm{PRW})^{1}$ is an initiative between members of the academic community to acknowledge the importance of peer review to scholarly research and publishing. The fifth Peer Review Week was celebrated all around the world during 16-20th September 2019. The week saw a diverse range of engaging presentations, panel sessions and innovations focused on the theme of "Quality in Peer Review”, discussing many different aspects of 'Quality', and the ways in which it manifests through various stages of the peer review process, as different forms of peer review, through the technical infrastructure, or being enhanced through the progressive actions of organisations and individuals.

This year a total of 44 industry experts from 30 different organizations were on the full Steering Committee, including European Association of Science Editors (EASE) Council member Bahar Mehmani co-chairing the event with Emily Jesper-Mir of Sense About Science, and EASE Vice-President Duncan Nicholas sitting on the Events and Outreach Committee. Along with these prestigious organisations, the Asian Council of Science Editors (ACSE) played a role in supporting the week of events, disseminating the important discussion of PRW \& information among its $7000+$ individual council members via the ACSE Official Blog, with posts during the week viewed by 1500 members and commented by 22 field experts. ${ }^{2}$

Other contributor organisations included American Chemical Society, Aries, BMJ, Center for Open Science, Editage, Elsevier, International Society of Managing and Technical Editors, ORCID, Publons, SAGE, Springer Nature, and Wiley. This year PRW featured over ten webinar sessions, a host of blog posts and website articles, the release of Publons community awards, ${ }^{3}$ and live workshops including the launch of a course in peer reviewing at Ghent University, Belgium. ${ }^{4}$

The webinars featured a session from Editage, presented by Duncan Nicholas, looking at different constructs of quality in peer review, how they are being measured, developed, improved and supported across the publishing industry and academia; ${ }^{5}$ a session from the Council of Science Editors ${ }^{6}$ discussing the pragmatic best practices needed for maintaining quality peer review when journals undergo structural and workflow adjustments; and a session hosted by Jessica Polka of ASAPBio $^{7}$ (an organisation promoting the adoption of preprints in the life sciences), featuring five different speakers addressing developing methods of increasing transparency in reviewing.

Two Reddit AMA sessions, curated by Janne Seppänen (Peerage of Science) and Meghan McDevitt (Journal of Pediatrics and International Society of Managing and Technical Editors were held during the week, and available online. ${ }^{8}$ The first session featured renowned statistical ethics investigator James Heathers and Springer Nature's Research Integrity Group's Maria Kowalczuk. The second session involved Denis Bourguet and Thomas Guillemaud, founders of Peer Community In... (a platform for creating communities of researchers around specific subjects, reviewing and recommending preprints). Together, both discussions received nearly 400 comments, 25,000 views, and 2.5 million impressions during the days of the sessions.

One of the core events which led up to the week was the official PRW YouTube Channel, ${ }^{9}$ curated by Duncan, which showcased over 30 video messages from experts around the globe, all discussing different perspectives on the Quality theme. The top videos from the PRW YouTube channel with the greatest numbers of views are shown in Table 1.

The videos present many interesting viewpoints from experienced researchers and members of the publishing industry that will serve as a useful reference resource on topics such as why peer review is important, why researchers review and how it benefits them, the benefits of training reviewers, why peer review is valuable to the public, aspects of reviewing which involve universities and institutions, and insights into the systems and technology that manage the process.

Several of the videos comment on Quality in Peer Review being something of an artform, with good reviewers communicating logical reasons for decisions to an editor with less experience, to help them determine whether the submitted manuscript is worthy of publication.

In her "Editor's View of a Good Review" video, Pippa Smart, President of EASE says "Good reviewers are worth 
Table 1: Top 5 most viewed videos according to the analytics of the PRW YouTube Channel

\begin{tabular}{|l|c|c|c|}
\hline Speaker's Name - Video Title & $\begin{array}{c}\text { Total } \\
\text { Views* }\end{array}$ & $\begin{array}{c}\text { Total } \\
\text { Likes* }\end{array}$ & URL \\
\hline Maryam Sayab - Peer Review and the ACSE & 549 & 26 & https://youtu.be/sm8BgPT6Ims \\
\hline $\begin{array}{l}\text { Raye-Ann deRegnier \& Paul Fisher - How to provide confidential } \\
\text { comments to editors }\end{array}$ & 381 & 8 & https://youtu.be/7Ln5B4Nu8AU \\
\hline Christopher Jackson - Fundamentals of Importance and Quality & 373 & 5 & https://youtu.be/QHInRmuoMQw \\
\hline Sam T. Mathew - On professional and pre-submission review & 158 & 8 & https://youtu.be/Pna-GZu2j38 \\
\hline Deborah Bowman - Peer reviewer mentorship programmes & 149 & 7 & https://youtu.be/9rmgSDG91jU \\
\hline
\end{tabular}

* (Last accessed on October 4, 2019)

to weigh in gold", ${ }^{10}$ and explains how easy it can be for reviewers to skip into criticising work without providing constructive comments. In her opinion, a good review is clear, succinct and always assesses article on the basis of valid research questions, sound methodology, credible results, logical discussion as well as righteous conclusions from the actual findings of research. She also added "Not every good researcher is a good reviewer and not every good reviewer is a good researcher."

Christopher Jackson, geologist at Imperial College, London highlighted the importance of peer review in his video message as "one of the several ways to improve quality of a piece of research and to make sure that it's logically laid out and clear enough for reasoning why and what was done for the sake of scientific literature?"11 In addition Dr. Paul Fisher, Associate Editor at The Journal of Pediatrics describes peer review as the "only tool to advance science and the respective research field, along with a chance of having the first glimpse of the best science in your own field". ${ }^{12}$

Dr Sam T Mathew, Ambassador of the ACSE, discusses the recent development in the peer review process of employing professional peer reviewers to get quality insights and significant contribution in a mutually-beneficial manner and pre-submission peer review, which provides expert subject area feedback to improves the quality of the manuscript prior to journal selection. ${ }^{13}$ Another modern issue was raised by Professor Mohammad Taha, British University in Egypt, who touched on the threat of predatory journals, explaining how "researchers from the Middle East, like in many other areas in the world, have started to resort to low quality open access journals", urging for caution with journal selection, and an attentive balance between speediness of publication and quality of peer review. ${ }^{14}$

Maryam Sayab provided a video describing the work the Asian Council of Science Editors have been doing to enhance quality in the region. She describes the development of a Reviewer Bank comprising recognised subject area experts, to facilitate and improve conventional peer reviewing processes of academic journals. ${ }^{15}$

Another initiative to improve the peer reviewing process was the Mentorship Practice explained by Deborah Bowman, Senior Managing Editor at American Society for Gastrointestinal Endoscopy. This practice supports young, new and inexperienced reviewers in learning the skills and art of quality reviewing by pairing them with expert reviewers who are known to do solid thorough reviews. ${ }^{16}$

A new approach of 'Consultative Peer Review' was shared by Willa Huston, Editor in Chief of Pathogens and Disease, to improve the quality of their peer reviews. She explained in detail about the procedure "where the editor kind of takes charge of the peer review process in order to liase between the peer reviews and the author; resulting into a really engaging and communicating peer review". ${ }^{17}$

The number of events held, and the audiences who engaged with them have been increasing each year of the event, and this year's Peer Review Week has been a big achievement for the Committee and everyone involved in contributing to the sessions. The week engaged a large number of industry experts, publishers, editors, and reviewers, encapsulating diverse experience, opinions, and suggestions, and builds on the mission and purpose of the initiative, by beginning to leave behind collections of useful resources that may be referred to in subsequent years. More than a celebration and acknowledgement of the value of peer review, the week is beginning to establish itself as an annual calendar event that will produce useful materials, and signpost significant advances and developments.

The PRW website holds all the links to activities from this year, and previous years, and will start to prepare for the 2020 events in the near future. 


\section{References}

1 Peer Review Week homepage. [Accessed 2019 October 3]. Available from: https://peerreviewweek.wordpress.com/

2 The ACSE 2019. Celebrating the Peer Review Week at ACSE. [Accessed 2019 September 20]. Available from: https://blog.theacse. com/2019/09/17/peer-review-week-2019-is-on-the-way/

3 Global Peer Review Awards 2019. Publons. [Accessed 2019 September 20]. Available from: https://publons.com/community/awards/2019/

4 Dissecting the peer review system: theory and practice. Ghent University, Doctoral Training School, 2019. [Accessed 2019 October 3]. Available from: https:/www.ugent.be/doctoralschools/en/doctoraltraining/ courses/transferableskills/all/peer-review-training-2019.htm

5 Duncan Nicholas, 2019. Webinar of Editage: Quality in peer review digging deeper. [Accessed 2019 October 3]. Available from: https:// www.editage.com/insights/quality-in-peer-review-digging-deeper/ 6 Compton D, Regala J, and Stanwood KG, 2019. Maintaining Quality Peer Review When Submission Trends and Journal Structures Change. CSE Webinar 4. [Accessed 2019 September 20]. Available from: https://customer.councilscienceeditors.org/cse/Register/cse/ Registration.aspx? eventkey=WEB190917

7 ReimagineReview community call 2: Revealing quality in peer review through increased transparency. ASAPBio, 2019. [Accessed 2019 October 3]. Available from: https://youtu.be/ZBXnl7wsTVU

8 AskScience AMA Series: We're James Heathers and Maria Kowalczuk here to discuss peer review integrity and controversies for part 1 of Peer Review Week, ask us anything! [Accessed 2019 October 3] Available from: https:/www.reddit.com/r/askscience/comments/ d5w2lq/askscience_ama_series_were_james_heathers_and/
9 Peer Review Week. [YouTube] [Accessed 2019 September 20]. Available from: https://www.youtube.com/peerreviewweek

10 Pippa Smart, 2019. An Editor's View of a Good Review. Peer Review Week [YouTube] 2019 August 2 [Accessed 2019 September 21]. Available from: https://youtu.be/hfxlqi8L5NI

11 Professor Christopher Jackson - Fundamentals of Importance and Quality. Peer Review Week [YouTube] 2019 July 24. [Accessed 2019 September 20]. Available from: https://youtu.be/QHlnRmuoMQw

12 Raye-Ann deRegnier \& Paul Fisher - How to provide confidential comments to editors Peer Review Week [YouTube] 2019 September 16 [Accessed 2019 September 20]. Available from: https://youtu. be/7Ln5B4Nu8AU

13 Dr. Sam T. Mathew - On professional and pre-submission review. Peer Review Week [YouTube] 2019 September 20 [Accessed 2019 September 21]. Available from: https://youtu.be/Pna-GZu2j38

14 Professor Mohammad Taha, 2019. Peer review in the Middle East. Peer Review Week [YouTube] 2019 September 18 [Accessed 2019 September 21]. Available from: https://youtu.be/k4YPhlrl77U

15 Maryam Sayab, 2019. Peer Review and the ACSE. Peer Review Week [YouTube] 2019 September 3 [Accessed 2019 September 21]. Available from: https://youtu.be/sm8BgPT6Ims

16 Deborah Bowman, 2019. Peer reviewer mentorship programmes. Peer Review Week [YouTube] 2019 August 20 [Accessed 2019 September 21]. Available from: https://youtu.be/9rmgSDG91jU

17 Willa Huston, 2019. Enhancing communication with consultative peer review. Peer Review Week [YouTube] 2019 September 16 [Accessed 2019 September 22]. Available from: https://youtu.be/xn78jiRJI9M

\section{Dates for your diary}

\section{2nd PEERE International Conference on Peer Review}

11th March 2020 - 13th March 2020

Dr Joon Seo Lim, Republic of Korea

Dr Victoria Vasilenko, Russian Federation

Mr Daniel Manrique-Castano, Germany

Dr Peter Seeber, Germany

Dr Sabina Alam, UK

Dr Kamilla Malinowska-Ozdowy, Austria

Prof Nelson Santiago Vispo, Ecuador

Dr Penny Drago, Australia

Mrs Anna Gredecka, Poland

\section{Group: Journal of Internal Medicine, Sweden}

Miss Thina Hedbom

Prof Rolf Hultcrantz

Prof Anders Ekbom

Prof Bo Angelin

Prof Jan Andersson

Prof Ulf de Faire

Prof Anna Nilsson

Prof Maria Lerm

Prof Karin Ekström-Smedby

Prof Olle Melander

Dr Per Dahlquist
Important dates 15 November 2019: Abstract \& paper submission deadline 10 January 2020: Notification to authors 11-13 March 2020: Conference in Valencia Scope Following the success of the 1st PEERE International Conference on Peer Review, the PEERE COST Action follow-up community organises the second edition of the PEERE International Conference on Peer Review in Valencia on 11-13 March 2020. The conference aims to provide a forum for scholars, practitioners and science stakeholders to share research, models, tools and experience...

For more information: www.ease.org.uk/events/ 